Revista de la red interuniversitaria de estudios sobre las literaturas rioplatenses contemporáneas en Francia

19 | 2018

La rebelión de los hijos: el judaísmo en la literatura latinoamericana contemporánea entre tradición y asimilación

\title{
Pragha-Austerlitz / Europa Mater
}

\section{Liliana Lukin}

\section{(2) OpenEdition}

\section{Journals}

Edición electrónica

URL: http://journals.openedition.org/lirico/6678

DOI: $10.4000 /$ lirico.6678

ISSN: 2262-8339

Editor

Réseau interuniversitaire d'étude des littératures contemporaines du Río de la Plata

Referencia electrónica

Liliana Lukin, «Pragha-Austerlitz / Europa Mater », Cuadernos LIRICO [En línea], 19 | 2018, Puesto en línea el 20 enero 2019, consultado el 30 abril 2019. URL : http://journals.openedition.org/lirico/6678 DOI : $10.4000 /$ lirico.6678

Este documento fue generado automáticamente el 30 abril 2019.

\section{cc) (i) (9)}

Cuadernos LIRICO está distribuido bajo una Licencia Creative Commons Atribución-NoComercial-

SinDerivar 4.0 Internacional. 


\title{
Pragha-Austerlitz / Europa Mater
}

\author{
Liliana Lukin
}

La lengua determinó en forma inequívoca que la memoria no es un instrumento para la exploración del pasado, sino solamente el medio. Así como la tierra es el medio en el que yacen enterradas las viejas ciudades, la memoria es el medio de lo vivido. Quien intenta acercarse a su propio pasado sepultado tiene que comportarse como un hombre que excava. Ante todo no debe temer volver siempre a la misma situación, esparcirla como se esparce la tierra, revolverla como se revuelve la tierra. Porque las "situaciones" son nada más que capas que sólo después de una investigación minuciosa dan a luz lo que hace que la excavación valga la pena, es decir, las imágenes que, arrancadas de todos sus contextos anteriores, aparecen como objetos de valor en los aposentos sobrios de nuestra comprensión tardía, como torsos en la galería del coleccionista. Sin lugar a dudas es útil usar planos en las excavaciones. Pero también es indispensable la palada cautelosa, a tientas, en la tierra oscura. Quién sólo haga el inventario de sus hallazgos sin poder señalar en qué lugar del suelo actual conserva sus recuerdos, se perderá lo mejor. Por eso los auténticos recuerdos no deberán exponerse en forma de relato sino señalando con exactitud en el lugar en que el investigador se apoderó de ellos. Épico y rapsódico en sentido estricto, el recuerdo verdadero deberá, por lo tanto, proporcionar simultáneamente una imagen de quien recuerda, así como un buen informe arqueológico debe indicar ante todo qué capas hubo que atravesar para llegar a aquella de la que provienen los hallazgos.

Walter Benjamin, El Desenterrar y recordar El deseo de unas ciudades, sí, de unas construcciones, de una arquitectura, de unos paisajes urbanos contaminados ya por el flujo de imágenes que los registran y hemos visto y leído (fotos, viajes anteriores, atlas, escenarios de vidas, films), el placer de ir en busca de algo ya conocido, para conocerlo 'en verdad', ordena y discierne el itinerario inicial de un viaje. Saber que hay una posibilidad, que es acotada en el tiempo y tener que decidir entre ciertos lugares, es el principio del dibujo de ese deseo. Después, definir desplazamientos elegidos, y por lo tanto inevitables, en un espacio geográfico, es también hacer intervenir el espacio resonante de unas lecturas.

El deseo de unas ciudades, decía, nos entregó una Berlín interminable: bella y terrible, Bienal, Museos, Teatros (Heiner Müller, Brecht, Bob Wilson, Bauhaus, Berlín Alexanderplatz, Potsdamer Platz y la huella del Muro), y me devolvía a Praga después de 25 años. 
Tomamos entonces un tren en Berlín, que salió de la estación principal hacia el sur este. Esas estaciones de la Europa central, que fueron bombardeadas hace más de 50 años, ahora acristaladas en verde, peceras gigantescas con ascensores, shoppings de partida y de llegada, marcan el ojo haciendo eco en imaginarios ya agotados de fantasías cinematográficas "siglo XXI": para el viajero, lujo y tecnología sobre unos hierros calcinados.

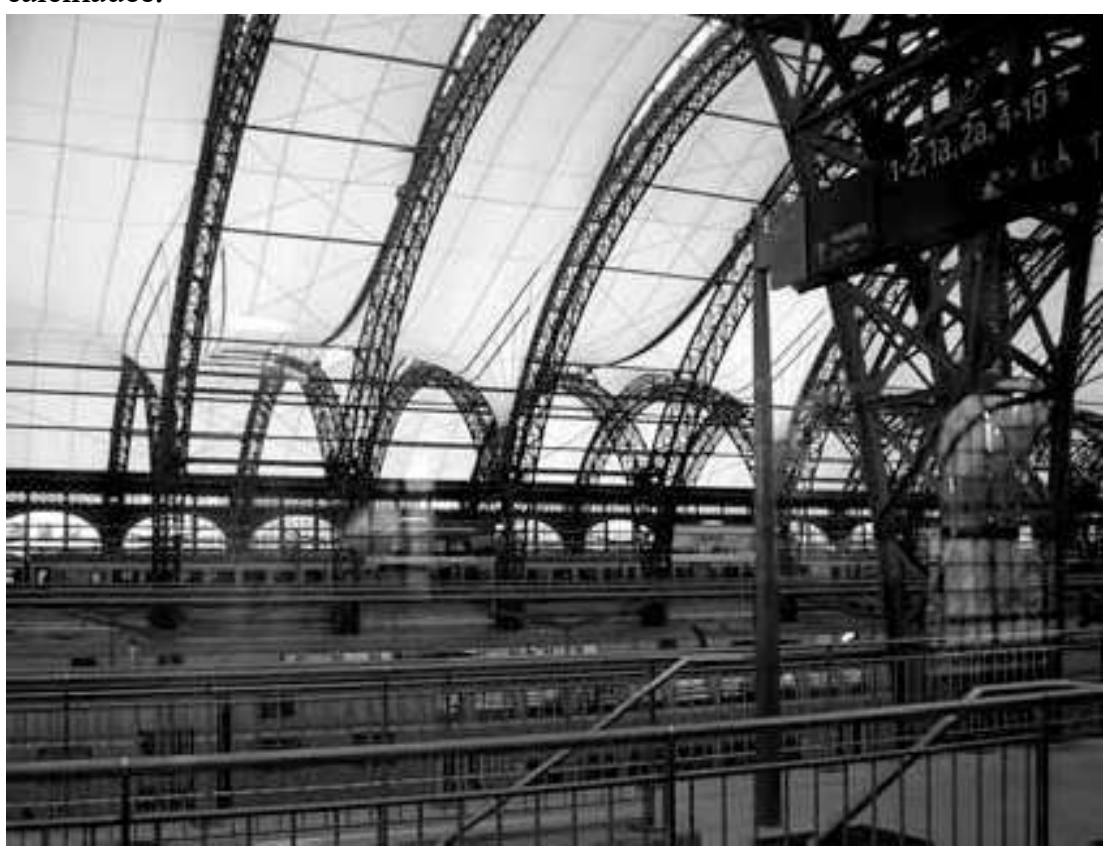

Salíamos de Alemania, habíamos estado allí, y en ningún momento, a pesar de haber atravesado en esos días, a duras penas, la experiencia a la que exponen el Museo Judío de Berlín, el monumento al Holocausto, la instalación callejera a perpetuidad por las calles del barrio donde vivió Einstein, la imponente sinagoga dorada, recientemente reconstruida y cerrada, y de haber visto los restos del Reichstag, atravesando la Puerta de Brandemburgo, en ningún momento, decía, a pesar de estas continuas inmersiones en un saber apremiante, angustioso, nominal, me percaté de que estaba siendo transportada en un tren alemán.

Aunque del otro lado del río que bordeaba las vías, en las laderas verdes y los peñones negros y afilados, altísimos, aparecieran los paisajes de Schindel y Friedrich, tenebrosos y cayendo perpendiculares en el agua, duplicados en el reflejo tranquilo. Escenarios donde asomaba tras un recodo un castillo que a la distancia parecía una casa apenas apoyada en las rocas, (imagen entre brumas del bunker del Führer en Moloch, la película de Sokurov). Un viaje pictórico: nos ofrecía el original de una iconografía que creíamos producto de la creación de los enfebrecidos "románticos alemanes", a quienes, además, habíamos admirado hacía unos días en las salas del palacio que es ahora su lugar de exposición. Y allí estaba esa cuasi naturaleza, disponible para obras realistas, que, como en casi toda experiencia "cultural", podíamos adjudicar a tal o cual referencia de una anterior apropiación: visiones que intentábamos reapropiar, literalmente, al ritmo del disparador de una cámara de fotos. 


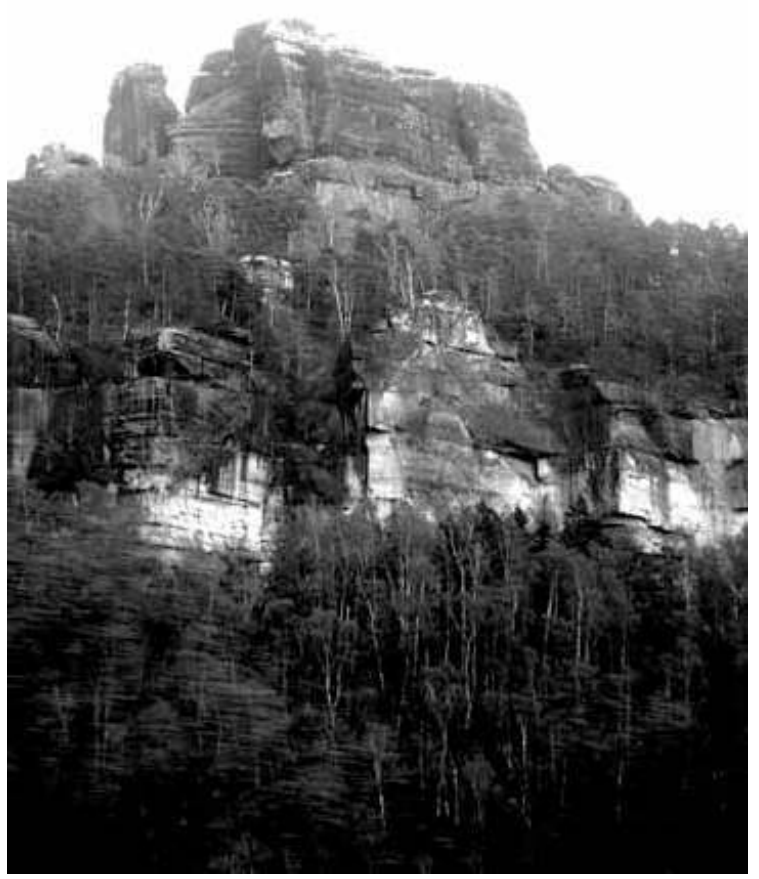

Era un viaje que atravesaba una frontera, un viaje internacional. El folleto impreso con los detalles de horarios y destinos que recibimos en el tren nos informaba que debíamos bajar en una estación anterior de la Central de Praga, que lamentablemente ya no conoceríamos (hoy supe, investigando, que está en refacción). Fue un descenso en la desorientación y la zozobra: con extrañeza, arrastrando el equipaje, habíamos llegado a destino, y parecía que hubiéramos bajado del tren que sale de Plaza Constitución, Buenos Aires, en la estación Banfield, que hoy sigue igual que en mi infancia. Holestovice es tan suburbana y gris como Banfield, aunque más limpia y menos deteriorada, a pesar de haber pasado la ocupación alemana, la guerra y un siglo más.

Yo llevaba, atesoraba para mi goce, las páginas fotocopiadas y abrochadas de la novela Austerlitz, de W.G.Sebald, publicada en 2002, desde el momento en que el protagonista, de 48 años, ignorante de su origen, descubre que puede haber sido uno de los miles de niños que salvaron su vida del nazismo siendo enviados por sus familias, en tren y después en barco, a Londres, donde los adoptaban familias inglesas. En esas páginas, él, por casualidad, escucha en la radio a unas mujeres que “[...] hablaban entre sí de cómo en el verano de 1939, siendo niñas, las habían enviado a Inglaterra en un transporte especial [... ] pero sólo cuando una de las dos comenzó a decir que su transporte, después de un viaje de dos días a través del Deutsche Reich y de Holanda, donde habían visto desde el tren las grandes aspas de los molinos de viento, había sido con el transbordador "Prague" de Hock a Harwich, por el Mar del Norte, supe, sin lugar a dudas, que aquellos recuerdos fragmentarios eran también parte de mi vida [...]".

Así es como al fin, no sin pasar por embajadas y oficinas, vuelve a Praga y se dirige al archivo estatal: se han conservado los papeles de la época, obtiene los domicilios de las personas con su apellido que vivieron allí entre 1934 y 1939, año de su viaje siendo un niño. Comienza la búsqueda del hogar primero. 
En 2008, como un ritual, haré por él ese camino: seguiré los pasos del personaje Austerlitz, con ese fragmento del texto en la mano, y veré de encontrar lo que él encuentra en la novela.

Vamos con Gustavo y con mi hijo, que está viviendo en Polonia, país de origen de sus abuelos, con su novia polaca conocida en Buenos Aires. Ya hemos visto los principales eventos del centro antiguo de la ciudad, es viernes y no llegamos a tiempo para entrar al cementerio judío, con sus losas inclinadas, al lado de la sinagoga pequeña que data de la llamada Edad Media.

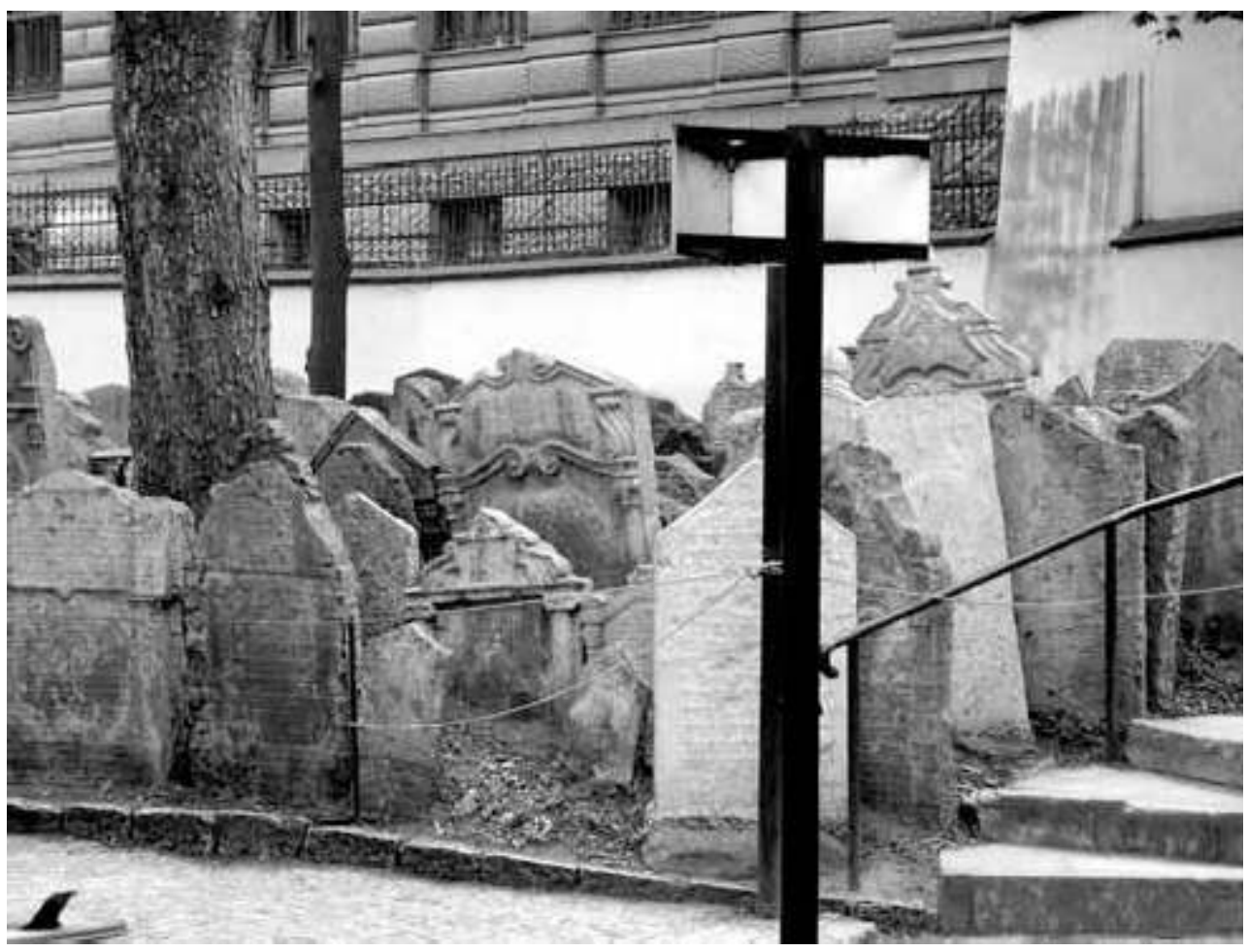

Recorremos encantados el barrio judío, volvemos al centro, es la tarde y la torre negra y todas las torres de un lado y otro del río, las agujas en las cúpulas, la alternancia de altura en los tejados y torres, recortan sus ya clásicos contornos góticos (que en la infancia creíamos propiedad de la fantasía de Walt Disney, y más tarde consumimos en toda clase de oscuras escenografías futuristas, copiadas para Batman y llevados al éxtasis por dibujantes de historietas postmodernas). 


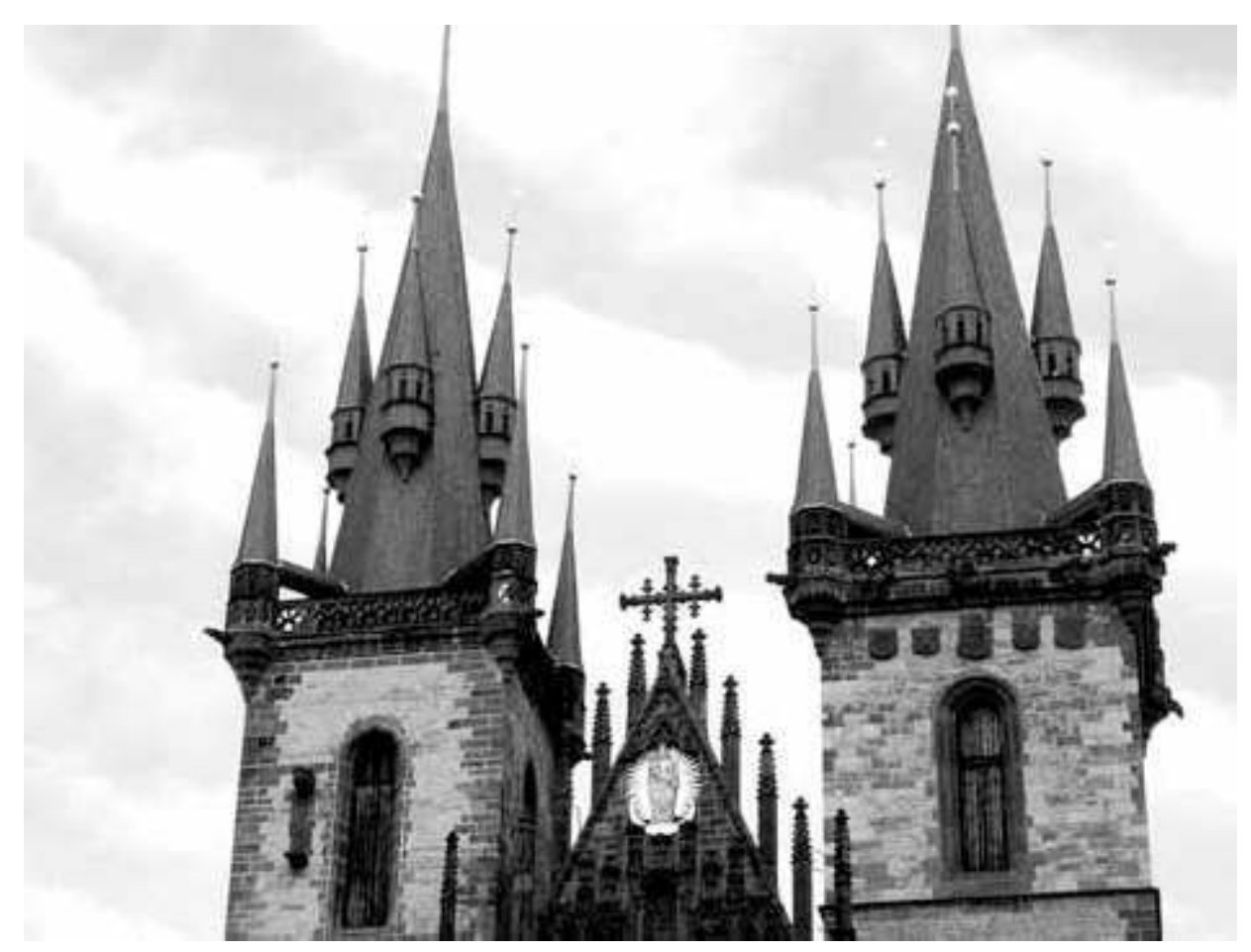

La reconstrucción de la ciudad ha restaurado cada detalle de los frentes, los verdes agua y dorado se repiten en las curvas de los balcones de hierro, lujo en la decoración de las paredes, en las vidrieras los cristales y diseños de principios de siglo espejan las veredas, es inevitable mirar hacia arriba, donde todo se eleva y divierte. El art nouveau y el art decó en las fachadas, el Teatro Negro y el Puppet Teather, inventos propios que conocimos a través del cine checo, el cubismo en el museo, en la cafetería, en la tienda de réplicas, y en la calle el edificio ondulante: las ideas artísticas que el siglo XX adjudica a las vanguardias, a la vista de todos.

En algún momento, saciada de admirar, decido que es hora de empezar a seguir el camino de Austerlitz, y saco de mi mochila las fotocopias abrochadas, unas cincuenta páginas que no incluyen el viaje del protagonista a Terezin, adonde fuera deportada su madre en 1941, como le es revelado, sino que se interrumpen cuando la vecina, Vera, su antigua niñera, le muestra una foto de él mismo con 5 años, disfrazado de caballero, (se reproduce en esa página la imagen, que es la de la tapa del libro) y Austerlitz dolorosamente exhuma sus sensaciones ante la foto y relata un sueño donde sus padres regresan. 


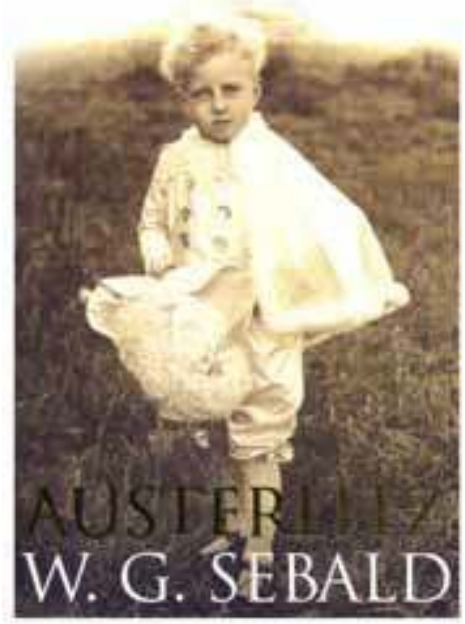

Mis acompañantes, cómplices en la búsqueda, descifran en el plano de la ciudad las calles nombradas en la novela. Descubrimos que, estando en la plaza antigua, debemos cruzar al otro lado del famoso puente Károl, con sus esculturas a todo lo largo y de cada lado de la travesía, por lo que bajo la llovizna pertinaz, que es casi una constante de la primavera, avanzamos con la masa de turistas que pareciera estar yendo desde siempre y sin interrupción, hacia el Hradcany (se pronuncia Jradshani), el Castillo, ese lugar emblemático que domina la vista.

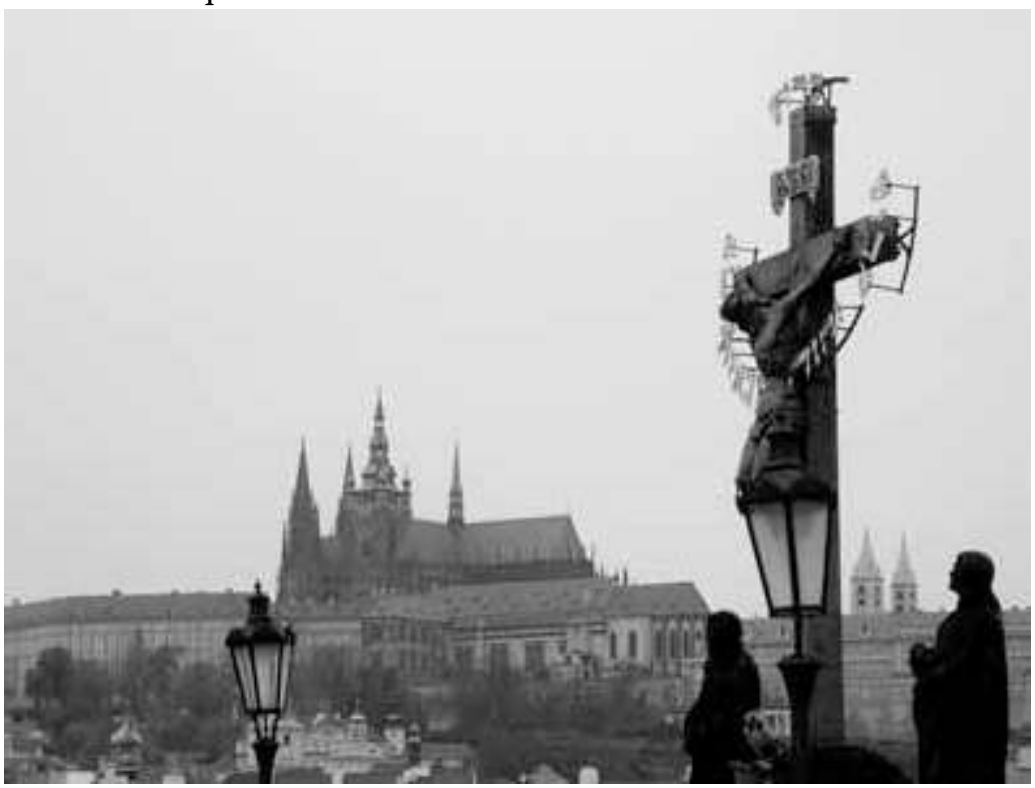

Yo he estado aquí, hace 25 años, en el mismo mes de abril, bajo la misma llovizna, subiendo por la empinada, escalonada avenida de adoquines: estaba embarazada, sin saberlo todavía, del hijo que ahora hace esta casi peregrinación conmigo.

Apenas cruzar, estamos ya en el Barrio Menor, pero el primer lugar visitado por Austerlitz, el Archivo estatal de la calle Karmelitska, está cerrado: primera desilusión, y no podremos ver su extraña estructura, minuciosamente descripta, que la novela reproduce en una de las tantas fotografías con que se completa y difiere la narración. Nosotros no tenemos tiempo de volver al día siguiente, como el personaje, y mientras fotografiamos cada puerta, leemos en voz alta: "La señora Ambrosová opinó que, antes de atravesar el río, debía empezar por el Barrio Menor, en la Sporkova, una pequeña calle 
situada algo más arriba del palacio de Schönborn, en la que, según el registro de habitantes de 1938, Agata Austerlitzová tuvo su vivienda en la casa nํㅜㄹ. Y así, dijo Austerlitz, apenas había llegado a Praga, había vuelto a encontrar el lugar de mi primera infancia, de la que, hasta donde podía recordar, se había eliminado todo rastro en mi memoria. Ya al dar vueltas en el laberinto de calles, por las casas y patios entre la Vlasská y la Nerudova, y totalmente cuando, subiendo paso a paso, sentí bajo los pies los adoquines irregulares de la Sporkova, fue como si hubiera recorrido antes esos caminos, como si se abriera para mí el recuerdo, no por el esfuerzo de recordar, sino por mis sentidos tanto tiempo entumecidos y ahora otra vez despiertos [...]".

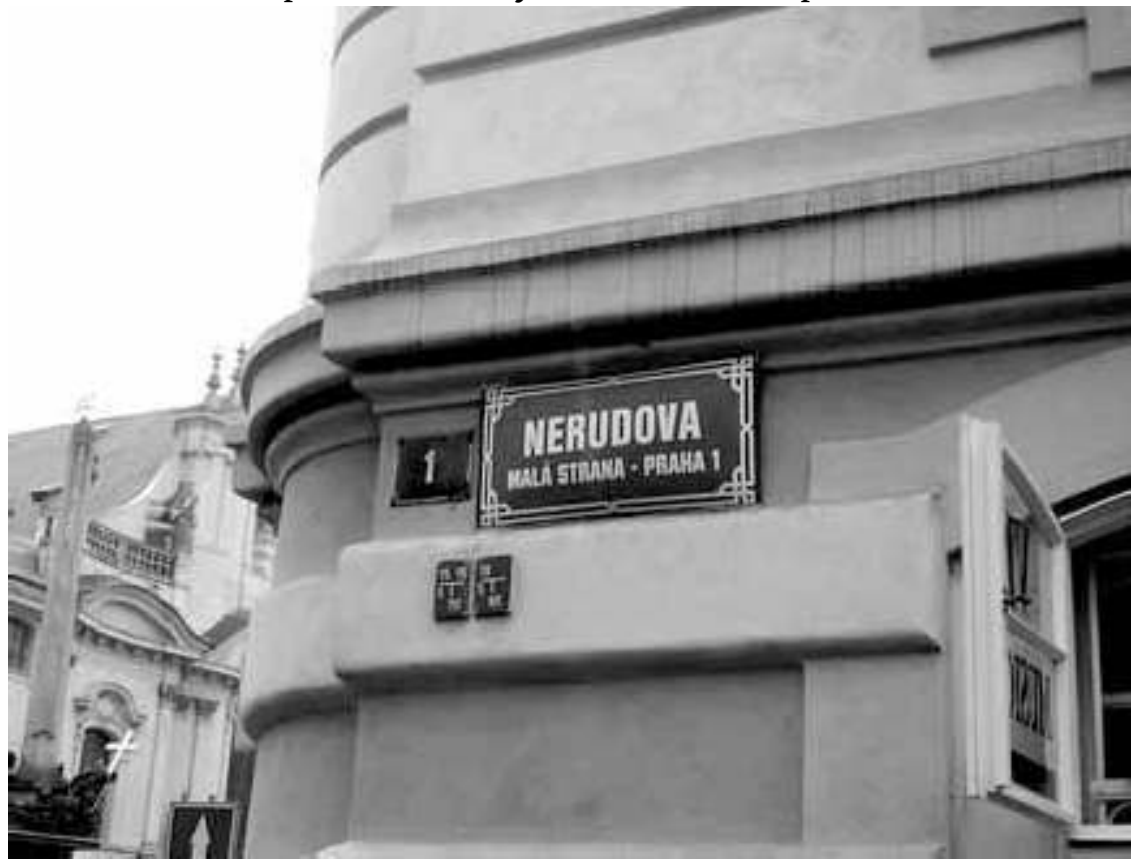

Seguimos al pie de la letra por la Nerudova (en homenaje a Jan Neruda, cuyos cuentos había leído antes de llegar, buscando algún dato más, alguna clave), en el Barrio de la Mala Strana, y avanzamos cada línea con él, eufóricos al encontrar las placas con el nombre de las calles, como si el hecho de que el escritor fuera fiel a la geografía de la ciudad, hiciera de nuestra Praga una ciudad más maravillosa. Y al dar una vuelta más, estamos ya en la calle Sporkova 12. Nos detenemos, fascinados, es aquí, aquí está, decimos y leemos en voz alta: "Y luego el aire fresco al entrar en el vestíbulo de la Sporkova no 12 , la caja de metal empotrada en la pared inmediatamente al lado de la entrada, para la electricidad, con el símbolo del rayo, la flor de mosaico de ocho hojas, gris paloma y blanco de nieve, en el manchado suelo de piedra artificial de la entrada, el olor a cal mojada, la escalera que ascendía suavemente, los botones de hierro en forma de avellana a intervalos determinados en el pasamanos de la barandilla..., nada más que letras y signos del cajón de imprenta de las cosas olvidadas, pensé y entré así en una confusión de sentimientos tan feliz y al mismo tiempo temerosa [...]".

Hemos llegado a la casa, pero está cerrada. Una fachada bien mantenida, blanca, demasiado importante para una casa de departamentos, pero la ficción no miente, el número existe, necesitamos ahora ver la baldosa de la entrada y la escalera que se reproduce en el libro, corroborar que, como Austerlitz, hemos dado con el hogar, el lugar olvidado y reencontrado, donde la unidad entre nuestra desesperación y nuestra esperanza será posible. Tocamos el timbre del portal. 


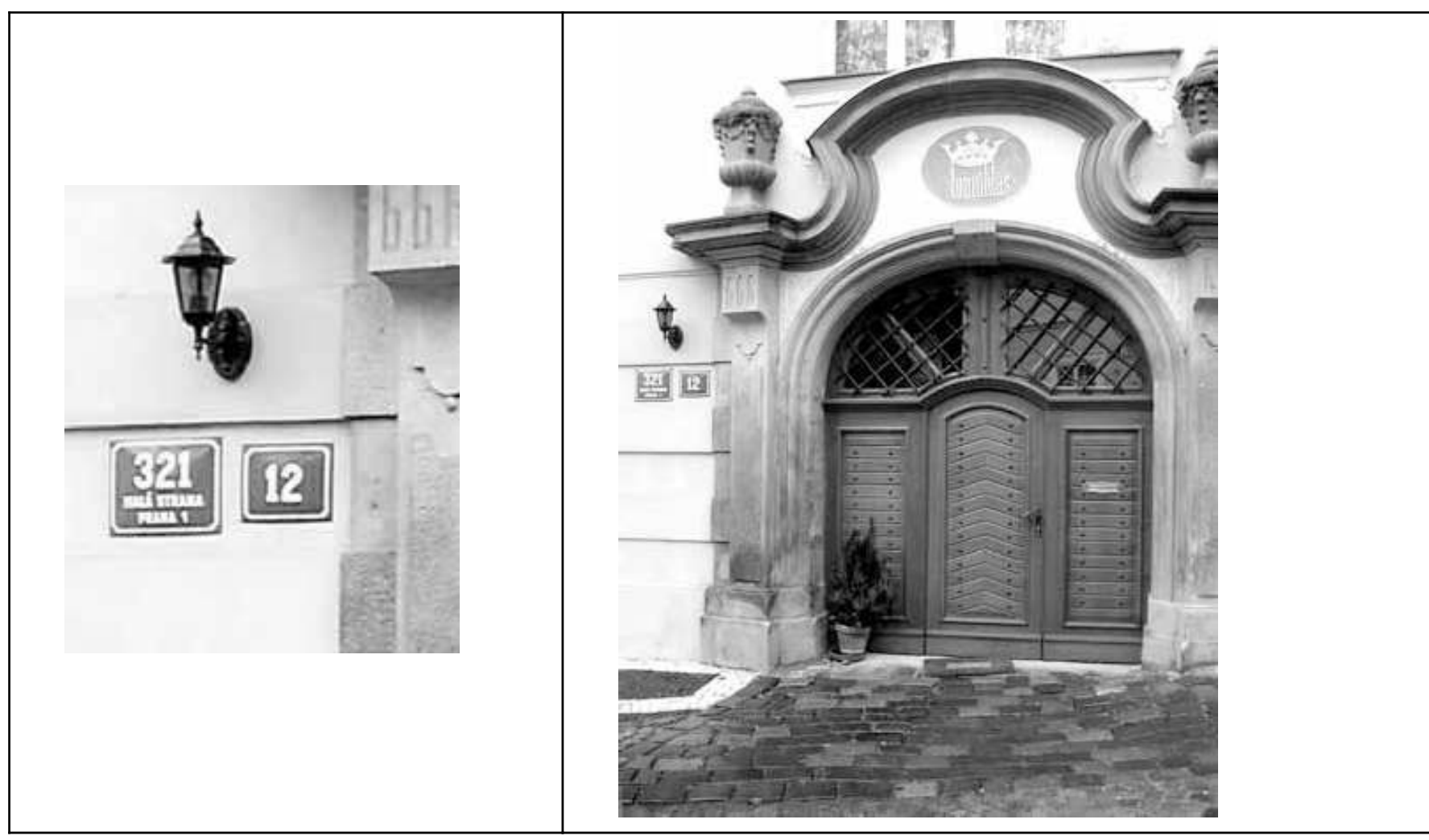

Lo que siguió podría ser una comedia, pero no se trata de algo gracioso, sino de la gracia de haber llegado. Contestaron en checo por el portero eléctrico, mi hijo explicó, en polaco, que queríamos pasar para ver la entrada, yo le digo lo que quiero que diga, le cuesta hacerse entender y después de un diálogo inescrutable con una voz femenina, sobreviene el movimiento de huida de mis dos partenaires, que intentaron renunciar diciendo no será aquí, no es esto, no entienden, vamos, y mi insistencia: casi gritando, en la calle empedrada de esta ciudad en el centro de Europa, donde ha vivido Kafka (hemos visto la casa de su infancia), que soy yo la que vengo desde Argentina, con una fotocopia en la mano, y que no me voy a ir de aquí hasta poder ver. Ver, corroborar, que el juego que he inventado en Buenos Aires se abre o se cierra. Se abre, apenas, la puerta, y una joven con uniforme de religiosa católica, que no entiende bien el polaco de mi hijo ni el inglés de mi compañero, mira lo que yo le señalo con el dedo, lo que pongo ante sus ojos: páginas de un libro, fotocopias de páginas de un libro, donde se lee claramente Sporkova 12 , y se ve una baldosa, una escalera, le señalo la página, el número en el portal al que ella se asoma, la calle, señalo hacia adentro, hacia el piso que no alcanzamos ni a vislumbrar porque lo obstruye con su cuerpo, señalo hacia nosotros y digo: Argentina, español, le hago leer la línea del texto, mira las fotocopias, me mira, decide algo, nos indica que esperemos. Avanza tres casilleros.

Vuelve con una monja mayor, que se presenta en inglés como la superiora, y mostrándole la página de la novela, repetimos la historia: queremos saber, queremos ver. Nos franquea la puerta, no hay ninguna baldosa, no hay, al fondo, ninguna escalera de hierro forjado, esto es la sede de una congregación de monjas francesas, nos explica, amable. No estamos seguros de que haya entendido el motivo de nuestra demanda, pero es amable, está allí ante unos extranjeros, perdidos, tal vez, que llevan en la mano un libro y piden por la casa, quién sabe, ella no desatenderá un llamado. Yo no me desvío de mi objetivo, 
pregunto de nuevo, hago que le pregunten en polaco, en inglés, desde cuándo esta casa es de una congregación religiosa, desde hace 100 años, responde, nos miramos, yo permanezco absorta, incrédula, insisto: más atrás del hall de entrada hay una puerta, señalo, ella nos invita a ir hacia allá mientras explica que cuando llegó el comunismo les sacaron la casa y la convirtieron en un instituto para niños no videntes, y que con la caída del Muro se la han restituido. Detrás de la puerta veo un patio, un jardín, otro edificio pequeño, del mismo estilo Tudor, y una pequeña construcción rectangular en el patio, pero veo, en el relato, un punto ciego: y antes de la guerra, qué había allí, pregunto, y ella contesta que la casa era de la congregación, aunque antes y durante la guerra fue un orfanato. Eso es. Silencio. Estupefacción, nosotros, los tres, tenemos una ráfaga de comprensión que se sofoca, estamos en el centro de una experiencia compleja que nos pertenece casi totalmente, no podemos hablar de ello. La monja nos invita a subir, arrastrados por lo envolvente de la situación vamos con ella por la escalera de mármol, nos cruzamos con otras monjas, en un rincón nos muestra un pesebre que parece una instalación de arte moderno, un enorme cuadro al revés apoyado en el suelo hace de fondo, al lado hay una puerta doble y la abre mientras nos indica silencio.

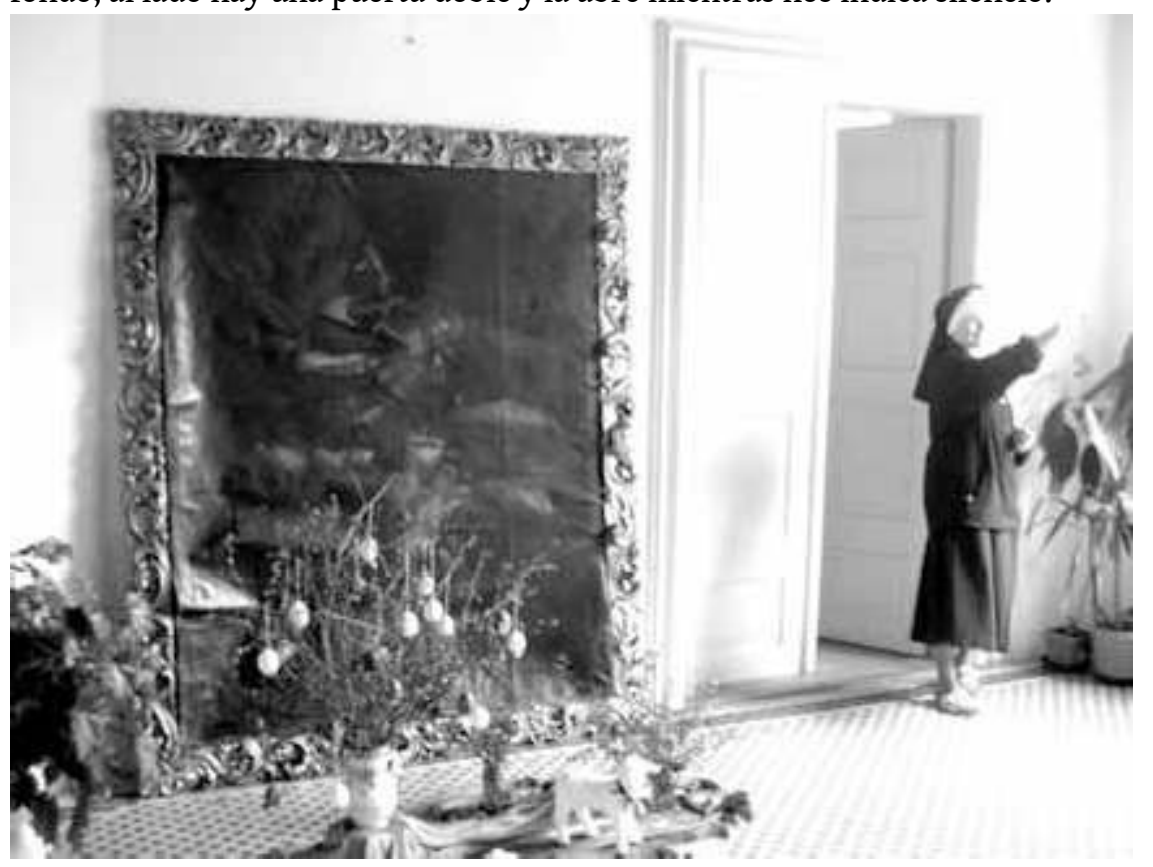

Yo accedo, primero veo los bancos largos con varias siluetas de espaldas y sé que estoy en la entrada de una capilla. En un solo movimiento, giro hacia el lugar de irradiación de la luz y veo que es un ventanal atravesado por el atardecer, con un altar delante hecho de lucecitas colgando en círculo del techo y un corazón de cristal rojo pendiente en el centro, sus rayos plateados de metal sueltos contra lo transparente. Tengo un golpe de emoción, una congoja, una aceptación del escenario, de su belleza cristalina y 'naif' y lloro, deslumbrada. Cuando me doy vuelta, en lo apenas entreabierto de la puerta, veo que mi hijo y Gustavo, que se quedaron apenas atrás, no han entrado, no han visto nada, no tenía yo cómo compartir lo singular de esa visión, ni mis lágrimas.

La superiora, cautivada, nos dedica su entusiasmo y nos muestra la pequeña construcción del patio, más antigua que el resto, su mural descascarado con una escena religiosa, original, nos dice, y abre la puerta de lo que debe haber sido una celda de retiro, donde aún brilla la pintura de una virgen en la pared sobre la que ahora se apoyan una escoba, un balde, trastos. 
Después vemos y fotografiamos un cuadrito con el registro fotográfico en blanco y negro del frente de la casa antes de su restauración actual: podemos conjeturar posterior a la guerra, oscuro y viejo.

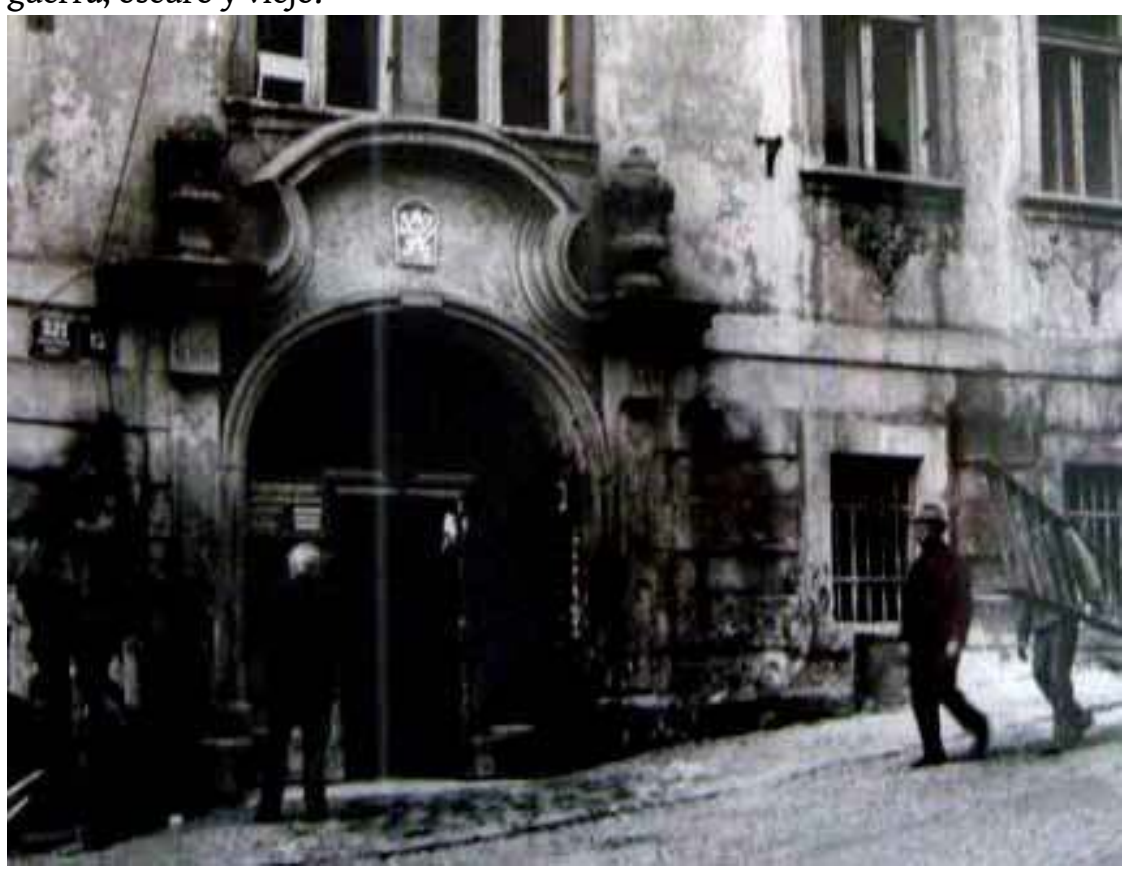

La evidencia es contundente, la congregación religiosa ha sido abierta a nuestros ojos, allí no hay un edificio de departamentos, no hay más que verosimilitud, y hemos sido conmovidos por W.G.Sebald, que nos llevó por la ciudad a lo que fuera un hogar de niños huérfanos en Praga, durante los años en los que el personaje de su ficción, Austerlitz, perdía primero el hogar, para después convertirse en huérfano.

Nos despedimos de esta señora tan cordial dándonos las manos, y al salir, ya balbuceando, atropelladamente, por la calle empedrada que desemboca en el nº 12 de la calle Sporkóva, inesperadamente damos con una pequeña cafetería en una casa con verja de hierro y jardín. Entramos, necesitamos tomar algo, repasar todo el asunto, es increíble, nos decimos, no sólo nos llevó W.G.Sebald a lo que fuera un orfanato, sino que hizo que Auterlitz, en la novela, reencontrara su hogar en Sporkóva 12. Donde esperábamos confirmar los rastros, la baldosa, la baranda de la escalera, que en las fotos reproducidas en la novela oficiaban de pistas 'reales' en la reposición de la memoria del personaje, en ese exacto lugar, nosotros confirmamos la ausencia total de esos rastros: pero el lugar existe y hubo allí un Hogar. Habíamos encontrado, como en toda buena literatura, pura metáfora.

Después, nos sacamos fotos tomando chocolate con strüdel en un juego de porcelana de Bohemia, felices, nostálgicos, con la sensación de haber hecho un buen trabajo, y salimos otra vez. 


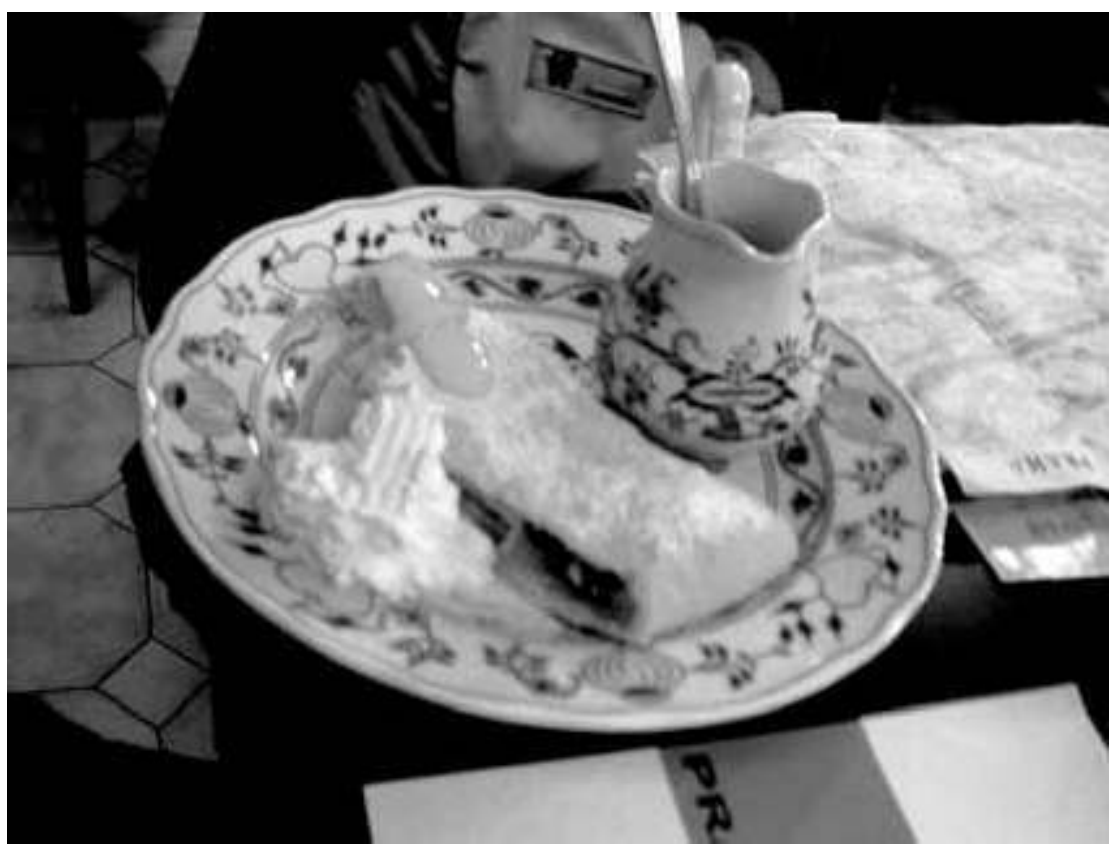

Estamos allí, en la intemperie, ha cesado la llovizna, hemos sido iniciados y ahora vamos hasta el final: al imponente Hradcany, a visitar su lujosísima Catedral, y después a la búsqueda, en ese laberinto dentro de los muros, del restaurante donde comí, aterida de frío en aquel paseo de 1983, una sopa parecida a la que hacía mi abuela. En su lugar, encuentro una tienda de objetos y compro una muñeca-marioneta y un huevo vaciado y pintado, en su cofre de plástico que apenas llegará entero al fin del viaje. Siguiendo el laberinto de esa ciudad dentro de la gran Praga, a unos metros encuentro la calle de los Artesanos del Castillo, de donde conservaba yo la foto de una ventanita adornada. El guardián nos deja pasar sin pagar la entrada sólo para fotografiarnos frente a las casas minúsculas. Repito entonces la experiencia, y los tres apreciamos sonriendo esas vidrieras como de juguete (ante las que hay que inclinarse), obsequiando así el pasado a nuestros ojos que agradecen.

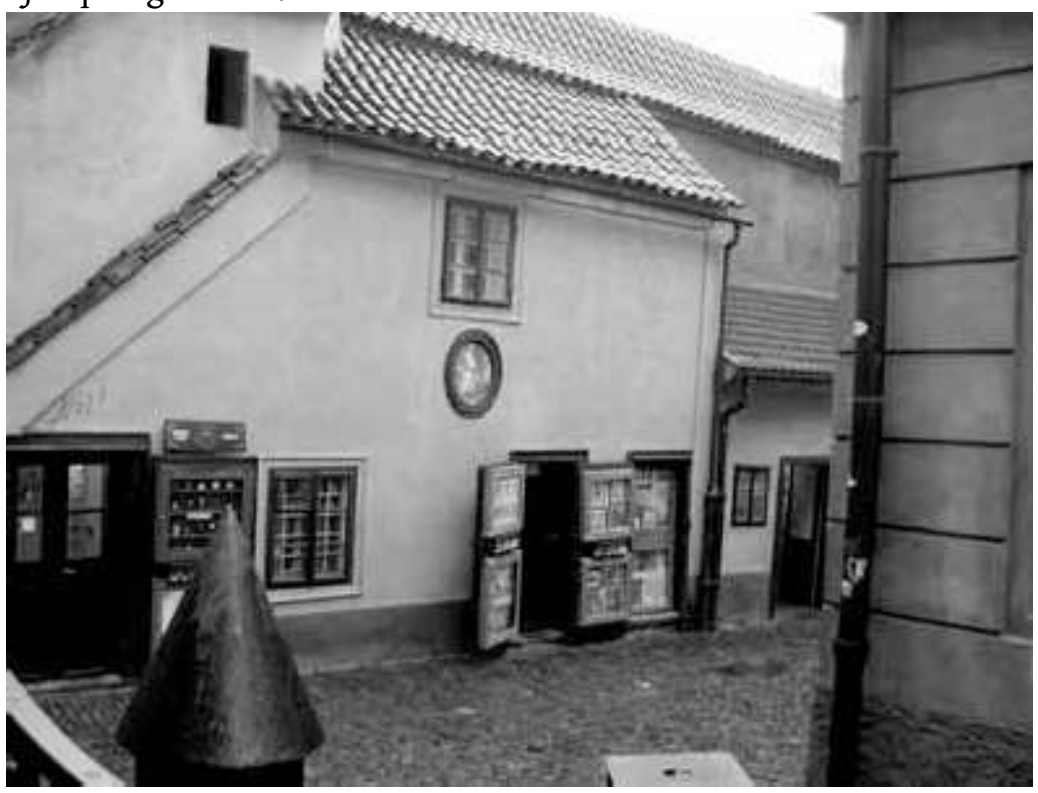

Hoy, 10 de enero de 2009, día en que al fin escribo este texto, apenas garabateado con dificultad desde el regreso a casa, en mayo de 2008, (inhibida de encontrar el momento, la 
concentración, la necesidad, afligida por la postergación), hoy, mi hijo cumple 25 años. El tiempo de su gestación, desde abril a enero, ha sido el tiempo de gestación de esta escritura: la obviedad de mi inconsciente no hace menos deslumbrante la repetición o la casualidad.

Siendo también el relato de viajes de mi voluntad en el trabajo de que el deseo de narrar se hiciera posible, esta historia es hija, por decirlo así, del cruce de varias líneas narrativas con las que me fueron reveladas en el transcurso de estos acontecimientos. El recuerdo siempre cultivado de unos episodios en esa ciudad, el placer de las asociaciones, la creación de historias para vivir en ellas, todo estaba allí en capas superpuestas. Un deseo anterior, que provocara la devoración perpetua de esa novela, y otro más antiguo, el de mi primera maternidad, se unían mientras íbamos en el trance de sostener Austerlitz como guía. Estas cajas chinas encierran, en un breve periplo, la historia del origen de dos seres vinculados por las lecturas y los viajes. La diferencia entre ellos estriba, entre otras graves cuestiones, en el hecho fundamental, en este caso, de haber tenido una biografía cruzada por la Shoah o posterior a ese Holocausto: dos vidas gestadas casi en el mismo lugar, a 50 años de distancia, por dos ficciones de distinto rango. El relato de este viaje, finalmente, es el relato de un viaje al origen. Dos protagonistas: un joven, hijo de judíos y nieto de inmigrantes polacos, rusos y rumanos, también judíos, pasea con su madre por Praga, y atisba apenas la metáfora de su concepción en una coincidencia que le es narrada en el sitio donde está sucediendo: abril de 1983, abril de 2008.

Esto ocurre mientras siguen, como un mandato, el recorrido que, en una novela, hace un hombre, judío checoslovaco, olvidado de sus primeros años, volviendo a Praga a principios de los años '90 donde recuperará, gracias a una coincidencia, la memoria más completa de su infancia mutilada en 1939 y del destino de sus padres, para advenir a la instancia de curarse de esa penosa enfermedad.

Cuando volvemos al hotel ordeno el contenido de la mochila: voy sacando los trofeos del día, la marioneta, un regalo para mi hija menor, que me pidió uno de esos globos de vidrios con nieve que contienen una reproducción en miniatura, (he conseguido uno con el Hradcany flotando entre los copos), el estuche de plástico con el huevo pintado, las fotocopias manoseadas de Austerlitz, restos de una vianda, mi cuaderno.

Y casi por no abandonar la novela, hago una relectura, avanzo un poco más allá del momento en que el personaje reproduce para su interlocutor los relatos que le hace la anciana Vera durante sucesivos encuentros, las diversas formas en que sus recuerdos reaparecen, y los episodios o asociaciones que llevan a Vera a contar lo que ya ella habría olvidado de no reaparecer Austerlitz en su vida. Así, encuentro que, unas páginas antes de que él decida viajar a Terezín, adonde su madre fuera deportada, Vera le cuenta: "Varios días duró la estancia en la barraca del Palacio de la Feria, hasta que finalmente, a primera hora de una mañana, cuando no había casi nadie por allí, fueron acompañados por guardias a la próxima estación de Holestovice, donde la 'vagonificación', como la llamaban, duró todavía casi tres horas. En épocas posteriores, dijo Vera, he hecho a menudo el camino de Holestovice, hasta el parque Stromovka y la Feria de Muestras, y la mayoría de las veces he ido al Lapidario, instalado allí en los años sesenta, [...] y me he preguntado sobre qué cimientos se asienta nuestro mundo."

Recuerdo entonces que nosotros bajamos en esa estación gris, suburbana, y que he anotado su nombre, y confirmo, en mi viejo cuaderno de notas, que en el viaje en tren desde Berlín a Praga descendimos en la estación de Holestovice. Esta coincidencia supera mi capacidad de asombro y debo rendirme al azar que rige y da sentidos a la vida: donde 
la madre de Austerlitz, Agata, fue 'vagonificada', y trasladada a Terezin, allí mismo nosotros bajamos de nuestro vagón, sesenta y siete años después, sólo porque, supe tardíamente, están refaccionando la Estación Central.

Si el deseo de unas ciudades organiza un viaje, dejar afuera del nuestro a Terezín provoca ya el deseo de otro viaje. El fragmento de la novela en el que Austerlitz espera el tren en Holestovice para ir a Terezín, su tránsito, el pueblo desierto, el museo del Gueto, su regreso a Praga y la despedida de Vera, antes de repetir el viaje que salvó su vida en 1939, cuando a los 5 años lo enviaron de Praga a Londres en tren, atravesando Alemania, puede ser el próximo fragmento a seguir.

A la mañana siguiente desocupamos la habitación, y arrastrando nuestras valijas, nos despedimos de mi hijo que vuelve a Cracovia. Hemos desayunado juntos, le he entregado los originales de los documentos de mis abuelos, que pueden servirle para tramitar en Polonia su doble nacionalidad, se lleva partidas de nacimiento (fechadas en 1897, en 1904, en Pruzhany, escritas en polaco y en ruso, donde todos son registrados como judíos), sus pasaportes de emigrantes sellados en Marsella entre 1929 y 1931, papeles. A cambio, me llevo regalos de él para sus amigos, para su hermana, para su padre, para sus abuelos, y entre abrazos y fotos de despedida, me pide que le deje la fotocopia de Austerlitz, que saco de mi mochila y le entrego gozosamente. El la guarda con cuidado en la suya, mientras subimos al taxi que nos lleva al aeropuerto, hacia Madrid.

\section{AUTOR}

\section{LILIANA LUKIN}

Universidad nacional de las Artes (Buenos Aires) 